\title{
Psicología Educativa
}

\section{Learning Potential is Useful in Pre-schoolers with Fragile X and Down Syndrome}

\author{
$\mathrm{M}^{\mathrm{a}}$ Auxiliadora Robles-Bello ${ }^{\mathrm{a}}$, Nieves Valencia-Naranjo ${ }^{\mathrm{a}}$, and David Sánchez-Teruel ${ }^{\mathrm{b}}$ \\ aUniversidad de Jaén, España; ${ }^{b}$ Universidad de Córdoba, España
}

\section{ARTICLE INFO}

Article history:

Received 24 May 2017

Accepted 28 November 2017

Available online 12 April 2018

\section{Keywords:}

Cognitive abilities

Learning potential

Down syndrome

Fragile X syndrome

Early intervention

Pre-school

\begin{abstract}
A B S T R A C T
This paper examines the performance of both Down syndrome (DS) and Fragile X syndrome (FXS) pre-schoolers in cognitive tasks of nonverbal reasoning and short-term memory (visual and auditory) and the ability to stimulate cognitive functions with a methodology of learning potential. It is the first study where this methodology is applied to FXS. The basic scales of the Escala de Habilidades y Potencial de Aprendizaje en Preescolares [Skills and Learning Potential Preschool Scale] were administered in 20 preschools with Down syndrome and 16 male preschools with Fragile X syndrome matched for chronological age and level of nonverbal cognitive development. The results indicated that the group FXS runs better on memory tasks without differences in reasoning tasks before mediation. Also, it is possible to stimulate the implementation in cognitive tasks of preschool children with DS or FXS significantly improving the performance of both groups except for auditory memory and DS in categorization rules. As conclusions, the scale offers the opportunity to assess skills in young children and know the degree of cognitive modifiability. Furthermore, possible factors affecting the performance of the children before and during mediation are discussed.
\end{abstract}

\section{El potencial de aprendizaje es útil en niños de educación preescolar con síndrome del cromosoma $X$ frágil y de Down}

\author{
R E S U M E N
}

Palabras clave: Habilidades cognitivas Potencial de aprendizaje Síndrome de Down Síndrome del cromosoma $\mathrm{X}$ frágil Atención temprana Educación preescolar

\begin{abstract}
Este trabajo analiza el desempeño de preescolares con síndrome de Down (SD) y X frágil (SXF) en tareas cognitivas de razonamiento no verbal y de memoria a corto plazo (visual y auditiva), así como la capacidad de estimular las funciones cognitivas con la metodología del potencial de aprendizaje. Se trata del primer estudio en el que se aplica esta metodología al SXF. Se administró las escalas básicas de la Escala de Habilidades y Potencial de Aprendizaje en Preescolares en 20 centros preescolares con síndrome de Down y en 16 centros preescolares masculinos con el síndrome del cromosoma $\mathrm{X}$ frágil emparejados por edad cronológica y nivel de desarrollo cognitivo no verbal. Los resultados indican que el grupo SXF funciona mejor en las tareas de memoria sin diferencias en tareas de razonamiento antes de la mediación. Igualmente, es posible estimular la aplicación en tareas cognitivas de niños de preescolar con SD o SXF, mejorando de un modo significativo el desempeño de ambos grupos, menos en memoria auditiva y en el caso de SD en reglas de categorización. Como conclusión, puede decirse que la escala brinda la oportunidad de evaluar destrezas en niños y conocer el grado de modificación cognitiva. Además, se comentan los posibles factores que influyen en el desempeño de los niños antes y durante la mediación.
\end{abstract}

Down syndrome and Fragile X syndrome (FXS) are among the intellectual disabilities most commonly associated with genetic factors (Gallagher \& Hallahan, 2012; Reilly, 2012). Both disorders share not only the presence of intellectual disability, but also a characteristic profile of strengths and weaknesses. The cognitive profile in these disorders falls under the "behavioral phenotype" concept (Fidler, Most, \& Philofsky, 2008; Reilly, 2012) and is influenced by genetic makeup as well as by other factors such as those of a behavioral nature (Calero, Robles-Bello, \& García, 2010; Carlier \& Roubertoux, 2010; Reilly, 2012; see Le Hellard \& Steen, 2014, for a review of the relationship between cognitive trends and genetic factors).

Patterson, Rapsey, and Glue (2013), in reviewing the profile of strengths and weaknesses in DS, reported significant limitations in short-term auditory/verbal working memory and intact implicit memory ability when compared with individuals of a similar mental age. Relative strength in visuospatial processing and nonverbal 
memory was also observed. In terms of executive functioning, Lanfranchi, Jerman, Dal Pont, Alberti, and Vianello (2010) found impairment effects among DS adolescents in relation to controls matched for mental age. Regarding the cognitive phenotype in FXS, Gallagher and Hallahan (2012) highlighted deficits in executive functioning, abstract reasoning, and short-term memory - especially the verbal kind and when the tasks call for sequential processing abilities - difficulties in attentional control and arithmetic, and poor visuospatial processing. As for their strengths, these included short-term memory when presented with simple and meaningful information, visual-perceptual recognition, and constructive skills.

Information related to phenotypes is of theoretical interest in itself, but on an applied level one of the main contributions is the design and implementation of interventions tailored to the characteristics of individuals (Davis, 2008; Fey, Finestack, Gajewski, Popescu, \& Lewine, 2010; Fidler \& Nadel, 2007; Finestack \& Abbeduto, 2010; Schwarte, 2008; Gallagher \& Hallahan, 2012). This process gives the option to approach intervention by focusing on strengths, which is a common strategy, or to work towards improving skill deficits (Conners, Rosenquist, Arnett, Moore, \& Hume, 2008). Both options stress the importance of recognizing children's performance traits. As such, the development of procedures aimed at identifying those abilities susceptible to improvement at different developmental stages may be relevant, given that development follows a nonlinear pattern in disorders (Kogan et al., 2009).

The assessment of children with special needs and/or young of age using instruments and methodologies developed for older children and/or adults present reliability and validity problems (Visser, Ruiter, van der Meulen, Ruijssenaars, \& Timmerman, 2012). An alternative to the traditional psychometric approach has been to assess the potential for learning ( Lidz \& Jepsen, 2003) in which a person, usually an adult expert, modifies - or mediates - the stimulus so that it can be registered more efficiently by the learner (Calero, 2004; Haywood \& Lidz, 2007). The methodology used to evaluate change associated with learning experiences involves an intervention process preceded and followed by a standardized assessment of the individual's performance (e.g., pre-test-intervention-post-test) (Haywood \& Lidz, 2007), providing us with information about child's performance level prior to intervention, but most especially cognitive modifiability when faced with the task (Tzuriel, 2013) and the tendency to change (Fabio, 2005). A comprehensive review of the principles and application of Dynamic Assessment as an evaluative approach can be found in Grigorenko (2009).

The possibility for cognitive stimulability in intellectual disabilities has been established in several studies: for example, in Alony and Kozulin (2007), Kozulin et al. (2010), Lifshitz, Tzuriel, and Weiss (2005) and Calero et al. (2010) relative to cognitive abilities; and in Robles-Bello and Calero (2003) in terms of reading. However, and as far as we are aware, no studies to date have applied this methodology in FXS.

The core objective of this study was to assess disabled young children's performance and, more specifically, compare and contrast DS and FXS pre-schoolers' performance on cognitive tasks related to nonverbal reasoning and short-term memory. In terms of this aim, we expected to see a response profile similar to that reported in literature, that is, a similar performance level in nonverbal reasoning and auditory memory tasks in both groups and stronger visual memory performance in DS preschoolers. The second objective was to identify whether intervention using a Learning Potential methodology impacts positively on performance in these cognitive tasks among DS and FXS individuals. Calero et al. (2010) recorded positive effects in preschoolers with DS using the Skills and Learning Potential Preschool Scale (Escala de Habilidades y Potencial de Aprendizaje en Preescolares - EHPAP). Thus, we expected to observe similar effects in the DS group of children included in this study. Given that we are unaware of studies which have applied this methodology in FXS, we have no benchmarks against which to measure, although we hypothesize that intervention will prove effective given the EHPAP's applicability in different populations and having found similarities in the DS and FXS phenotypes.

\section{Method}

\section{Participants}

Thirty-six preschoolers, 20 with DS ( 6 girls and 14 boys), aged between 4 and 6 years $(M=4.85, S D=0.99)$ and 16 boys with FXS, full premutation and aged between 4 and 5 years $(M=4.31, S D=$ $0.79)$ took part in the study. The groups did not vary in age $\left(t_{(34)}\right.$ $=1.77, p=.09)$ or in IC values $\left(t_{\text {manipulative(34) }}=.58, p=.57 ; t_{\text {verbal(34) }}=\right.$ $1.11, p=.28$ ), obtained using Kaufman, Cordero, and Calonge's (1997) Kaufman Brief Intelligence Test (KBIT).

\section{Material}

The Skills and Learning Potential Preschool Scale (EHPAP; Calero Robles-Bello, Márquez, \& de la Osa (2009) is an adaptation of the Application of Cognitive Functions Scale (ACFS) (Lidz \& Jepsen, 2003).

The EHPAP assesses cognitive abilities distributed across 4 basic scales, Classification (CL), Auditory Memory (AM), Visual Memory (VM), and Series (S), namely those applied in this study. Each scale uses a pretest-intervention/training-posttest format. During training, a trained mediator guides the implementation of cognitive strategies to ensure that the activity is carried out successfully. The pretest and posttest phases also involve the same task or another very similar one without the evaluator's assistance.

The EHPAP scales are as follows:

1. Classification: to group blocks according to their feature dimensions (e.g., colour, shape, and size). The amount of blocks grouped together and the number of groups made are assessed.

2. Auditory Memory: to reproduce/retell a story. The number of details included and correct temporal sequences are assessed.

3. Visual Memory: to recall previously presented objects. The number of items recalled and the number of strategies used to recall this information are assessed.

4. Series: to complete pattern sequences. The number of sequences completed and the number of sequences completed and valid explanations about the choices made were assessed.

\section{Procedure}

All children were participating in an Early Childhood Intervention (ECI) programme. DS children came from the same centre; FXS children attended different centres across the region but followed an ECI programme with similar characteristics. Once informed consent was received from the parents, the EHPAP basic scales were administered by two psychologists trained in this assessment during one-on-one sessions.

The mediation that takes place between examiner and learning respondent during training is traditionally carried out (Haywood \& Wingenfeld, 1992b) using the Learning Potential Methodology. The objective is to try to alter the test application situation, so after administering the pretest, the facilitator interacts with the respondent, employing "mediation," which is defined in general terms by Haywood and Wingenfeld (1992a) as a process-oriented dialog characterized by (Lidz, 2002): 1) intentionality, which aims to bring about cognitive change; 2) transcendence - this attempts a structural change that can be generalized to other situations; 3 ) meaning - the mediator enhances and guides the child's perceptual experience, helping him or her decide what to focus on and what to continue noticing; 4) competence, 
showing the subject what aspects of their behavior are effective and reinforcing what they do well, while also bringing their attention to anything that seems like an obstacle to their learning, all so the child trusts that they can perform well; 5) regulation of behavior and goal seeking, setting, and achievement - this sets rules, at first external, that are later internalized: 6) sharing - the examiner should make the child aware of other people's experiences and thoughts to enrich their own experience; 7) task regulation - new learning is presented in a way that promotes the child's competency and mastery, as well as strategic, planned thinking; 8) challenge - every learning situation posed aims to elicit a level of functioning in the child that surpasses their current level, and to reach a higher level than in the previous situation; 9) psychological differentiation - the examiner should fulfill their role, to facilitate learning while avoiding the temptation to be overly instructive, and the child should likewise allow him or herself to be mediated; 10) contingent responsivity - the facilitator should respond to the child in a timely, appropriate way; and 11) affective involvement - the facilitator should transmit warmth and caring to the child to build a rapport, and also so the interaction will be pleasant for both parties.

The Appendix presents a sample procedure and mediation from the Perspective Taking subscale (Calero et al., 2009).

\section{Design}

The design included Group variables on two levels according to child's diagnosis (DS, FXS) and the two-tier Moment variable (pre, post), which represented the scores obtained pre- and postintervention in Classification (CL), Auditory Memory (AM), Visual Memory (VM), and Series (S) scales corresponding to the EHPAP.

\section{Results}

Data was analyzed using SPSS 19.0. In order to examine the first objective, DS and FXS performance was tested using pairwise comparisons at pretest for $\mathrm{CL}, \mathrm{AM}, \mathrm{VM}$, and $\mathrm{S}$. The invention effect was examined by means of repeated measures ANOVAs on these same tasks. In this case, Cohen's $d$ was used to obtain intervention effect size.

The pairwise comparison of independent samples showed the Pretest FXS scores to be significantly higher than those obtained for DS in AM, $t_{(34)}=4.00, p<.001$, and VM, $t_{(34)}=2.35, p<.05$, with no differences recorded in $\mathrm{CL}, t_{(34)}=1.75, p=.09$, and $\mathrm{S}, t_{(34)}=1.14, p=.26$. Means and standard deviations are shown in Table 1 and Figure 1.

Table 1. Pre-test and Post-test Scores on each EHPAP Subscale in the SD and FXS Groups

\begin{tabular}{|c|c|c|c|c|c|c|c|c|}
\hline & \multicolumn{4}{|c|}{ DS } & \multicolumn{4}{|c|}{ FXS } \\
\hline & \multicolumn{2}{|c|}{ Pre } & \multicolumn{2}{|c|}{ Post } & \multicolumn{2}{|c|}{ Pre } & \multicolumn{2}{|c|}{ Post } \\
\hline & $M$ & DT & $M$ & $D T$ & $M$ & $D T$ & $M$ & $D T$ \\
\hline Classification (C) & 2.75 & 0.91 & 3.00 & 1.52 & 3.25 & 0.77 & 5.06 & 1.56 \\
\hline Auditory Memory (AM) & 0.55 & 0.68 & 0.80 & 1.05 & 1.69 & 1.01 & 2.25 & 1.77 \\
\hline Visual Memory (VM) & 2.00 & 1.07 & 3.25 & 1.44 & 2.87 & 1.15 & 4.38 & 2.09 \\
\hline $\begin{array}{l}\text { Sequential Pattern } \\
\text { Completion }(S)\end{array}$ & 1.25 & 1.16 & 1.55 & 0.94 & 1.94 & 2.37 & 3.06 & 2.51 \\
\hline
\end{tabular}

In terms of the second objective, the main effects of Moment, $F_{(1,34)}=13.65, p<.001$, and Group, $F_{(1,34)}=16.94, p<.001$, were significant in CL, as well as in Moment $x$ Group interaction, $F_{(1,34)}=7.83$, $p<.05)$. Pairwise comparisons in the interaction revealed post values to be significantly higher than pre values for FXS, $t_{(15)}=4.53, p<.001$, $d=1.15$, but not for DS, $t_{(19)}=.653, p=.522$.

The effects of Moment, $\left.F_{(1,34)}=3.86, p=.06\right)$ in AM and Moment $\mathrm{x}$ Group failed to reach significance, $\left.F_{(1,34)}=.57, p=.455\right)$, but did so for Group, $F_{(1,34)}=15.158, p<.001$, with higher values observed for FXS (see Table 1).
The main effect of Moment in VM was significant, $F_{(1,34)}=16.592$, $p<.001, d_{\mathrm{DS}}=0.86, d_{\mathrm{FXS}}=0.72$, yielding higher values at post-test, and for Group, $F_{(1,34)}=7.712, p<.05$, with higher average scores in FXS (see Table 1). The Moment $\mathrm{x}$ Group interaction was not significant, $F_{(1,34)}$ $=.137, p=.713$.

As for Series, the significant main effects were in Moment, $F_{(1,34)}=4.205, p<.05, d_{\mathrm{DS}}=0.32, d_{\mathrm{FXS}}=0.43$, yielding higher values at post-test and Group, $F_{(1,34)}=4.64, p<.05$, with higher average scores observed in FXS (see Table 1). The Moment x Group interaction, $F_{(1,34)}=1.409, p=.243$ ) failed to reach significance.

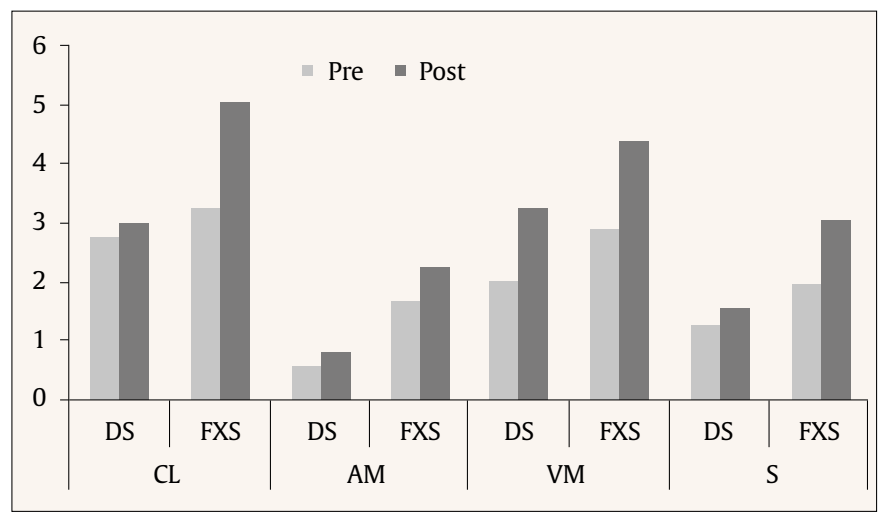

Figure 1. Means Comparison between DS and FXS Groups in the EHPAP Pretest and Post-test Situations on CL, AM, VM, and S subscales.

\section{Discussion}

The first aim of this study was to compare and contrast DS and FXS pre-schoolers' performance in nonverbal reasoning and shortterm memory tasks prior to intervention. The second objective was to identify whether adult-led intervention influenced their performance. Both objectives are now discussed in relation to each of the cognitive tasks.

Classification calls for the categorization of stimuli based on their feature dimensions (e.g., colour, shape and size) and is an explicit learning process driven by forming hypotheses about discrete categories (Phillips, Conners, Merrill, \& Klinger, 2014). This type of categorization is deficient in FXS (Van der Molen et al., 2010) and in DS (Philips et al., 2014), and we did not expect to find differences between the groups, given the difficulties in nonverbal reasoning ability identified in both groups (Reilly, 2012). The pre-intervention results coincide with this prediction and support the conclusion reached by Phillips et al. (2014) that this categorization type is more likely to be linked to intellectual disability than to the etiology of this disability.

Conners, Moore, Loveall, and Merrill (2011) suggested that the deficiency in rule-based categorization is related to limitations in executive functioning components. In terms of these components, Phillips et al. (2014) highlighted the contribution of working memory without definitively excluding other components (e.g., inhibition of irrelevant categories and the ability to deviate the set). Intervention conducted on CL was shown to have a significant positive effect in FXS $(d=1.15)$ but without affecting DS performance. This finding suggests the possibility of improving rule-based categorization performance in FXS pre-schoolers perhaps linked to a more effective executive functioning, at least when compared with DS. The strategies aimed at integrating skills in this group during intervention (e.g., simple learning, visual-perceptual recognition and constructive skills) may have enhanced their performance.

The absence of positive effects in DS was unexpected as it differed from the findings recorded by Calero et al. (2010). The participants 
in this study showed weaker IC and the discrepancy between these findings suggests that classification involves later development in DS, or that a greater number of tests are required in order to stabilize learning (Patterson et al., 2013; Tsao \& Kindelberger, 2009). The material used during intervention, that is, drawing of figures which combine different characteristics of shape, size and colour, may have imposed high demands on the inhibition of irrelevant stimuli, and especially in set deviation. Memisevic and Sinanovic (2014) found inhibition to be difficult for children with intellectual disabilities, whereas Garon, Bryson, and Smith (2008) concluded that development in the ability to deviate the set comes after that of working memory and inhibition. Furthermore, these researchers believe that the better established the initial representation, the more complicated the deviation between representations, when there is conflict between them, if the stimulus needs to be processed differently, and if there is overlapping between the categories. The action of grouping based on these features may have been particularly difficult for the DS children given that the materials share similar characteristics and because it is necessary to deviate the set among previously reinforced conditions.

Lanfranchi, De Mori, Mammarella, Carreti, and Vianello (2015) highlighted the need to distinguish two dimensions in working memory. The first is the level of attentional control required and the second the task presentation format. When the attentional demands are high, for example, in the case of active tasks, intellectual disabilities usually show a general impairment. Passive tasks, the group that involves AM and VM, are related to short-term memory span measures. In these passive tasks, Lanfranchi et al. (2015) suggested that it is possible to observe dissociation in performance according to the etiology of the disability and influenced by the presentation format (e.g., verbal, visuospatial, and spatial-sequential).

Auditory memory deficits have previously been identified in DS (Lanfrachi, Carretti, Spanó, \& Cornoldi, 2009) and in FXS (Baker et al., 2011, Gallagher \& Hallahan, 2012). The prediction regarding AM was about similar difficulties in both groups prior to intervention, in line with findings by Shapiro et al. (1995) (taken from Baker et al., 2011) among adults. Despite this, FXS individuals performed stronger than their DS peers. Vicari, Verucci, and Carlesimo (2007) found that problems in AM were influenced by limitations in the ability to perform phonological, semantic, and syntactic processing tasks. Along the same lines, Kyttälä, Aunio, and Hautamäki (2010) found deficits in working memory (verbal and visuospatial) to be associated with linguistic abilities in children who display difficulties in mathematics learning, but which were not moderated by fluid intelligence. These abilities are superior in FXS when compared with DS (Price et al., 2008) and which might explain the stronger FXS performance in this task.

In terms of AM intervention, both groups demonstrated increased performance following this mediation, but using visual images to aid memory only had a marginally significant effect and showed the difficulty in improving this function in DS and FXS. Conners et al. (2008) also found that a memory span training programme among DS individuals produced limited and focused effects in a group of children.

We expected DS at Pretest to obtain higher scores than FSX in VM. The results go against our predictions with FXS performance being significantly higher. This finding was unexpected although it was obtained by Kogan et al. (2009). Furthermore, Baker et al. (2011) found that memory span in a visual task in FXS, despite being weaker than that of controls, surpassed that obtained in auditory memory.

Lanfranchi and colleagues suggested that the visuospatial function may be compromised in DS in memory tasks that require simultaneous processing - the items are shown together - as opposed to a sequential processing - items presented one after another (Carreti, Lanfranchi, \& Mammarella, 2013; Lanfrachi, Carretti et al., 2009a; Lanfranchi et al., 2015), whereas in FXS this impairment reveals itself when high attentional demands are imposed by the task (Lanfranchi, Cornoldi, Drigo, \& Vianello, 2009). The format of the VM task, in which the stimuli were presented together, may have forced simultaneous processing, a strength that stands out in FXS (Cornish, Cole, Longhi, Karmiloff-Smith, \& Scerif, 2012) and imposes limitations in DS.

Another salient finding in VM is the effect associated with intervention. The ability to improve the recall of visual material using repetition-based strategies, grouping items and visual images (e.g., details) is significant in both groups $\left(d_{\mathrm{DS}}=0.86, d_{\mathrm{FXS}}=0.72\right)$. It has not been possible to identity in this study what or which of these strategies may have contributed to performance, or even if the same strategies have been used. However, encouraging the use of strategies may have facilitated children's performance given that Edgin, Pennington, and Mervis (2010) associated the limitations in memory span in DS children with restrictions in the spontaneous use of recall strategies. Equally, the restructuring of material using these strategies may have compensated for the difficulties involved in integrating information about the stimuli (e.g., analysis of their features), facilitating the development of representations, an aspect that Lanfranchi et al. (2015) consider relevant in simultaneous processing. Good FXS performance coincides with their ability to process concurrent information. What is more, the incentive to use recall strategies involves the central executive (Edgin et al., 2010), a function that has been kept relatively intact in FXS participants in this study if we take into account the CL results.

Categorization in Series requires a system that integrates stimuli dimensions by means of the covariance experienced in different examples. This learning is defined by Phillips et al. (2014) as implicit. Vicari et al. (2007) concluded that the ability to learn from the experience without a conscious reference to said experience is a skill usually found in those with intellectual disabilities, although not uniformly across all disorders (e.g., performance was strong in DS but poor in Williams syndrome on a procedural task). In the present study, DS and FXS reached similar levels of performance at pre-test for Series, supporting the conclusion drawn by Vicari et al. (2007) that implicit learning ability is relatively independent from the etiology associated with intellectual disability and from reasoning skills (DS showed improved performance in $S$ but not in $C L$ ).

The findings of Bussy, Charrin, Brun, Curie, and des Portes (2011) regarding implicit learning in DS and FXS are similar to those obtained by Vicari et al. (2007), who found that implicit learning, albeit intact in DS, is sensitive to interference, proving efficient in FXS. These findings coincide with the effect intervention had on improving performance in S, where FXS $(d=0.43)$ demonstrated a stronger performance than the DS group $(d=0.32)$. The inclusion during intervention of examples presented using different modalities (e.g., visual, verbal and gestural) may have limited DS children's learning capacity, acting as an interference feature during the learning process.

With this study we aimed to identify whether performance by DS and FXS preschoolers differed on cognitive tasks covered in the EHPAP. We also wanted to find out if it was possible to improve performance using Learning Potential methodology. We are unaware of studies that assess cognitive modifiability in children with FXS. The findings suggest that pre-intervention performance is similar across both groups in nonverbal reasoning tasks, whereas the abilities of FXS individuals are stronger in memory tasks. Similarly, we found that cognitive abilities may be enhanced by using directed interaction strategies. The profile that emerged from intervention was not the same for both groups. Nonverbal reasoning ability improved for FXS individuals in rule-based categorization and for both groups in establishing patterns, although the gains were limited. Furthermore, it has proved possible to improve recall in both groups using a visual modality, which was particularly effective in DS. We believe that the tasks and intervention procedure used have had a significant impact on all results obtained, offering us a way of assessing cognitive abilities in young children evoking strengths and weaknesses related to these etiologies. 


\section{Conflict of Interest}

The authors of this article declare no conflict of interest.

\section{References}

Alony, S., \& Kozulin, A. (2007). Dynamic Assessment of receptive language in children with Down syndrome. International Journal of Speech-language Pathology, 9, 323-331. https://doi.org/10.1080/14417040701291415

Baker, S., Hooper, S., Skinner, M., Hatton, D., Schaaf, J. C., Ornstein, P., \& Bailey, D. (2011). Working Memory subsystem and task complexity in young boys with Fragile X syndrome. Journal of Intellectual Disability Research, 55, 19-29. https://doi.org/10.1111/j.1365-2788.2010.01343.x

Bussy, G., Charrin, E., Brun, A., Curie, A., \& des Portes, V. (2011). Implicit procedural learning in fragile $X$ and Down syndrome. Journal of Intellectual Disability Research, 55, 521-528. https://doi.org/10.1111/ j.1365-2788.2011.01410.x

Calero, M. D. (2004). Validez de la evaluación del potencial de aprendizaje [The validity of the learning potencial assessment]. Psicothema, 16, 217-221. http://www.psicothema.com/pdf/1185.pdf

Calero, M. D., Robles-Bello, M. A., \& García, M. B. (2010). Habilidades cognitivas, conducta y potencial de aprendizaje en preescolares con síndrome de Down. Electronic Journal of Research in Educational Psychology, 8, 87-110. http://www.investigacion-psicopedagogica.org/ revista/new/index.php? $\mathrm{n}=20$

Calero, M. D., Robles-Bello, M. A., Márquez, J., \& de la Osa, P. (2009). EHPAP: Evaluación de Habilidades y Potencial de Aprendizaje para Preescolares. Madrid, España: Editorial EOS.

Carlier, M., \& Roubertoux, P. (2010). Genetics and Cognition: The Impact for Psychologists in Applied Settings. European Psychologist, 15, 49-57. https://doi.org/10.1027/1016-9040/a000007

Carreti, B., Lanfranchi, S., \& Mammarella, I. C. (2013). Spatial-simultaneous and spatial-sequential working memory in individuals with Down syndrome: The effect of configuration. Research in Developmental Disabilities, 34, 669-675. https://doi.org/10.1016/j.ridd.2012.09.011

Conners, F. A., Moore, M. S., Loveall, S. J., \& Merrill, E. J. (2011) Memory profiles of Down, Williams, and fragile $X$ syndromes: Implications for reading development. Journal of Developmental and Behavioral Pediatrics, 32, 405-417. https://doi.org/10.1097/ DBP.0b013e3182168f95)

Conners, F. A., Rosenquist, C. J., Arnett, L., Moore, M. S., \& Hume, L. E. (2008). Improving memory span in children with Down syndrome. Journal of Intellectual Disability Research, 52, 244-255. https://doi.org/10.1111/ j.1365-2788.2007.01015.x

Cornish, K., Cole, V., Longhi, E., Karmiloff-Smith, A., \& Scerif, G. (2012) Does attention constrain developmental trajectories in fragile $X$ syndrome? A 3-year prospective longitudinal study. American Journal on Intellectual and Developmental Disabilities, 117, 103-120. https:// doi.org/10.1352/1944-7558-117.2.103

Davis, A. S. (2008). Children with Down syndrome: Implications for Assessment and Intervention in the School. School Psychology Quarterly, 23, 271-281. https://doi.org/10.1037/1045-3830.23.2.271

Edgin, J., Pennington, B. F., \& Mervis, C. B. (2010). Neuropsychological components of intellectual disability: the contributions of immediate, working, and associative memory. Journal of Intellectual Disability Research, 54, 406-417. https://doi.org/10.1111/j.13652788.2010.01278.x

Fabio, R. A. (2005). Dynamic assessment of intelligence is a better reply to adaptive behavior and cognitive plasticity. The Journal of General Psychology, 132, 41-64. http://search.proquest.com/ docview/213646784?accountid=14555

Fey, M., Finestack, L., Gajewski, B., Popescu, M., \& Lewine, J. (2010). A Preliminary Evaluation of Fast ForWord-Language as an Adjuvant Treatment in Language Intervention. Journal of Speech, Language, and Hearing Research, 53, 430-449. http://www.finestackclil.com/wpcontent/uploads/2014/03/Fey-et-al.-2010.pdf

Fidler, D. J., Most, D. E., \& Philofsky, A. D. (2008). The Down syndrome behavioural phenotype: Taking a developmental approach. Down Syndrome Research and Practice. Advance online publication.

Fidler, D. J., \& Nadel, L. (2007). Education and children with Down syndrome: neuroscience, development and intervention. Mental Retardation and Developmental Disabilities Reviews, 13, 262-271. https://doi. org/10.1002/mrdd.20166

Finestack, L. H., \& Abbeduto, L. (2010). Expressive Language Profiles of Verbally Expressive Adolescents and Young Adults with Down Syndrome or Fragile X Syndrome. Journal of Speech, Language, and Hearing Research, 53, 1334-1348. https://doi.org/10.1044/10924388(2010/09-0125

Gallagher, A., \& Hallahan, B. (2012). Fragile X-associated disorders: A clinical overview. Journal of Neurology, 259, 401-413. https://doi.org/10.1007/ s00415-011-6161-3

Garon, N. Bryson, S. E., \& Smith, I. M. (2008). Executive function in preschoolers: A review using an integrative framework. Psychological Bulletin, 134, 31-60. https://doi.org/10.1037/0033-2909.134.1.31
Grigorenko, E. L. (2009). Dynamic assessment and response to intervention. Two sides of one coin. Journal of Learning Disabilities, 42, 111-132. https://doi.org/10.1177/0022219408326207

Haywood, H. C., \& Lidz, C. S. (2007). Dynamic Assessment in Practice: Clinical and Educational Applications. New York, NY: Cambridge University Press.

Haywood, H. C., \& Wingenfeld, S. (1992a). Interactive Assessment as a Research Tool. The Journal of Special Education, 26, 235-268. https:/ doi.org/10.1177/002246699202600303

Haywood, H. C., \& Wingenfeld, S. (1992b). The Learning test Concept: Origins, State of the Art and Trends. In H. C. Haywood \& D. Tzuriel (Eds.), Interactive Assessment (pp. 64-93). New York, NY: SpringerVerlag.

Kaufman, N. L., Cordero, C., \& Calonge, I. (1997). K-bit: Test breve de Inteligencia de Kaufman. Madrid, España: TEA Ediciones.

Kyttälä, M., Aunio, P., \& Hautamäki, J. (2010). Working memory resources in young children with mathematical difficulties. Scandinavian Journal of Psychology, 51, 1-15. https://doi.org/10.1111/j.1467-9450.2009.00736.x

Kogan, C. S., Boutet, I., Cornish, K., Graham, G. E., Berry-Kravis, E., Doruin, A. \& Milgram, N. W. (2009). A comparative neuropsychological test battery differentiates cognitive signatures of Fragile $X$ and Down syndrome. Journal of Intellectual Research, 53, 125-142. https://doi.org/10.1111/ j.1365-2788.2008.01135.x

Kozulin A., Lebeer, J., Madella-Noja, A., Gonzalez, F., Jeffrey, I, Rosenthal, N., \& Koslowsky M. (2010). Cognitive modifiability of children with developmental disabilities: a multicentre study using Feuerstein's Instrumental Enrichment-Basic program. Research in developmenta disabilities, 31, 551-559. https://doi.org/10.1016/j.ridd.2009.12.001

Lanfrachi, S., Carretti, B., Spanó, G., \& Cornoldi, C. (2009). A specific deficit in visuospatial simultaneous working memory in Down syndrome. Journal of Intellectual Disability Research, 53, 474-483. https://doi.org/10.1111/ j.1365-2788.2009.01165.x

Lanfranchi, S., Cornoldi, C. Drigo, S., \& Vianello, R. (2009). Working memory in individuals with fragile $\mathrm{X}$ syndrome. Child Neuropsychology: A Journal on Normal and Abnormal Development in Childhood and Adolescence, 15, 105-119. https://doi.org/10.1080/09297040802112564

Lanfranchi, S., De Mori, L., Mammarella, I. C., Carreti, B., \& Vianello, R. (2015). Spatial-sequential and spatial-simultaneous working memory in individuals with Williams syndrome. American Journal of Intellectual and Developmental Disabilities, 120, 193-202. https://doi. org/10.1352/1944-7558-120.3.193

Lanfranchi, S., Jerman, O., Dal Pont, E., Alberti, A., \& Vianello, R. (2010). Executive function in adolescents with Down syndrome. Journal of Intellectual Disability Research, 54, 308-319. https://doi.org/10.1111/ j.1365-2788.2010.01262.x

Le Hellard, S., \& Steen, V. M. (2014). Genetic architecture of cognitive traits. Scandinavian Journal of Psychology, 55, 255-262. https://doi. org/10.1111/sjop.12112

Lidz, C. S. (2002). Mediated Learning Experience (MLE) as a basis for an alternative approach to assessment. School Psychology International, 23, 68-84.

Lidz, C. S., \& Jepsen, R. H. (2003). Application of Cognitive Functions Scale (ACFS). Technical Manual (Unpublished manuscript).

Lifshitz, H., Tzuriel, D., \& Weiss, I. (2005). Effects of training in conceptual versus perceptual analogies among adolescents and adults with intellectual disability. Journal of Cognitive Education and Psychology, 5, 144-167. https://doi.org/10.1891/194589505787382504

Memisevic, H., \& Sinanovic, O. (2014). Executive function in children with intellectual disability -the effects of sex, level and aetiology of intellectual disability. Journal of Intellectual Disability Research, 58, 830-837. https://doi.org/10.1111/jir.12098

Patterson, T., Rapsey, C. M., \& Glue, P. (2013). Systematic review of cognitive development across childhood in Down syndrome: implications for treatment interventions. Journal of Intellectual Disability Research, 57, 306-318. https://doi.org/10.1111/j.1365-2788.2012.01536.X

Phillips, B. A., Conners, F. A., Merrill, E., \& Klinger, M. (2014). Rulebased category learning in Down syndrome. American Journal of Intellectual and Developmental Disabilities, 119, 220-234. https://doi. org/10.1352/1944-7558-119.3.220

Price, J. R., Roberts, J. E., Hennon, E., Berni, M. C., Anderson, K. L., \& Sideris, J. (2008). Syntactic complexity during conversation of boys with fragile X syndrome and Down syndrome. Journal of Speech, Language and Hearing Research, 51, 3-15. https://doi.org/10.1044/10924388(2008/001

Reilly, C. (2012). Behavioural phenotypes and special educational needs: Is aetiology important in the classroom? Journal of Intellectual Disability Research, 56, 929-946. https://doi.org/10.1111/j.1365-2788.2012.01542.x

Robles-Bello, M. A., \& Calero, M. D. (2003). Evaluación del Potencial de Aprendizaje dela lectura en Síndrome de Down. Siglo Cero Revista Española sobre Discapacidad Intelectual, 206, 14-26. http://riberdis. cedd.net/handle/11181/3060

Schwarte, A. R. (2008). Fragile X Syndrome. School Psychology Quarterly, 23, 290-300.

Tsao, R., \& Kindelberger, C. (2009). Variability of cognitive development in children with Down syndrome: relevance of good reasons for using the cluster procedure. Research in Developmental Disabilities, 30, 426432. https://doi.org/10.1016/j.ridd.2008.10.009 
Tzuriel, D. (2013). Mediated learning experience strategies and cognitive modifiability. Journal of Cognitive Education and Psychology, 13, 5980. https://doi.org/10.1891/1945-8959.12.1.59

Van der Molen, M. J. W., Huizinga, M., Huizenga, H. M., Ridderinkhof, K. R., Van der Molen, M. W., Hamel, B. J. C., \& Ramakers, G. J. A. (2010). Profiling Fragile X Syndrome in males: Strengths and weakness in cognitive abilities. Research in Developmental Disabilities, 31, 426439. https://doi.org/10.1016/j.ridd.2009.10.013

Vicari, S., Verucci, L., \& Carlesimo, G. A. (2007). Implicit memory is independent from IQ and age but not from etiology: evidences from Down and Williams syndromes. Journal of Intellectual Disability Research, 51, 932-941. https://doi.org/10.1111/j.13652788.2007.01003.x

Visser, L., Ruiter, S. A. J., van der Meulen, B. F., Ruijssenaars, A. J. J. M., \& Timmerman, M. E. (2012). A review of standardized developmental assessment instruments for young children and their applicability for children with special needs. Journal of Cognitive Education and Psychology, 11, 102-127. https://doi.org/10.1891/1945-8959.11.2.102 


\section{Appendix}

\section{Sample Procedure and Mediation from the Perspective Taking Sub-Scale}

\section{Materials}

Colored pencils or chalk of the child's choosing and 6 sheets of size A4 white paper. A picture of a kid, a cat, and a bear on separate sheets. Pretest: Take the picture of the KID, along with the pencils and sheets of white paper. Place a sheet of paper in front of the child and another before the examiner. Put the picture in-between the examiner and the child, and the pencils above the picture. Say "Now we are going to do something a little different. I want YOU to be my teacher. I want you to help me draw this picture. Teach me how to draw a picture of this kid. What do I need to do?" If the child vacillates or starts to draw, say right away: "Don't forget! You're the teacher. Teach me or tell me how to draw the picture."

If the child starts to give instructions and later stops or makes a mistake, prompt them again, say: "Don't forget! You need to teach me how to draw the picture." If the child gives instructions or makes verbal comments, the facilitator draws exactly what they say. In other words, the examiner does not wait for the child to tell them to draw.

\section{Training-Mediation}

Set the CAT drawing, a sheet of white paper, and the pencils in front of the child and examiner. Say: "Good. Now it is my turn to be the teacher. I am going to teach you how to draw this cat. Which pencil do you want to use?" Model teaching with verbalizations and demonstration: the order in which to draw; ways to create the cat's body parts; where to put lines or parts of the cat's body; details about what to do.

\section{Posttest}

Place the BEAR picture, the pencils, and two white pieces of paper as in the pretest. Say: "Now it is your turn to be the teacher. Teach me how to draw this picture of a bear. What do I need to do? Don't forget; you have to teach me how to do this." 